\title{
Optimization of operating parameters for a 600MW Rankine cycle based Ultra Supercritical power plant
}

\author{
Peyyala Nagasubba Rayudu ${ }^{1}$, Dr. K. GovindaRajulu ${ }^{2}$ \\ ${ }^{1}$ Research Scholar, Dept. of ME, JNTUA, Anantapuramu - 515003, \\ Associate professor, Dept. of Mechanical Engineering, \\ Madanapalle Institute of Technology \& Science, Madanapalle - 517325 \\ ${ }^{1}$ rayudup@mits.ac.in \\ ${ }^{2}$ Professor \& Principal, JNTUA College of Engineering Pulivendula, \\ Pulivendula, AndhraPradesh -516 390, India \\ 2govindjntu@gmail.com
}

\begin{abstract}
Priority of any power generation plant is reduction in heat rate, improved conversion of low grade energy into high grade energy and increased thermal efficiencies. Increase in coal costs, Green environment protection and related global regulations led the researchers to invent new ways to improve the efficiency of power plants. This technical study aims at optimizing the various technical parameters for the selected 600MW Rankine cycle based Ultra Supercritical (USC) power plant. The energy and exergy destructions and efficiencies would be estimated by varying the number of feedwater heaters, bled steam pressures and deaerator pressures of power plant. Also aimed to optimize the number of feedwater heaters during this study. While carrying out this study, the operational constraints of the individual thermal equipment's are taken into consideration.
\end{abstract}

Keywords: Ultra Supercritical, exergy analysis, energy analysis, feedwater heater, deaerator

\section{INTRODUCTION}

Based on the statistical data from International Energy Agency (Association, 2016) the Thermal energy is the highest source of power across world. With regeneration process or including the feedwater heaters, it is possible to increase the average heat addition of any steam power plant. Higher enthalpy which is available with the supercritical and ultra supercritical steam enables the thermal power plants to achieve higher efficiencies. So, there is a scope for the study to optimize the technical thermal parameters, in order to achieve the higher power plant efficiencies. Yuanyuan et.al[1]in his comprehensive study on USC Power plant, used a ten stage regenerative and double reheat system to optimize its parameters for higher efficiency. Power plant efficiency increase of $2 \%$ is observed i.e $44.78 \%$ to $46.83 \%$ by introducing double reheat instead of single reheat. Sandhya et. al[2], in her work analyzed a 422 MW power plant by using Lignite fuel, identified the highest exergy destruction in furnace (86\%), 82\% in Turbine, is reported. Zhi et. al[3], in his work investigated the influence of condenser pressure on power plant and exergy efficiency for which he considered a 500MW steam power plant,and concluded that, about $43.5 \%$ fuel cost reduction is possible by using the high grade coal(SA grade) instead of low grade (SM grade) coal . Rosen M.A et. al[4], conducted a study to compare the coal fired and nuclear power plants on the basis of exergy and energy. During which he considered a $500 \mathrm{MW}$ power plant and derived and compared various exergitic and energetic losses. And it is observed that only $30 \%$ to $33 \%$ of exergy efficiency is being found in his research analysis. Rayudu et.al[5], in their study concluded that, the steam at elevated temperatures and pressures certainly improves the performances of rankine cycle.

During the literature review, it is observed that, there is a significant scope to optimize the number of feedwater heaters, bled steam pressures and deaerator pressures of a power plant, for a better exergy and energy efficiencies when they operate at supercritical and ultra-supercritical conditions. A 600MW NTPC power plant is being considered, a simulated software model is developed by using Matlab software, in order to carryout the parametric optimization. Also these findings are validated with the realistic data available at an NTPC power plant.

The following parameters are being considered for the study and optimized to achieve highest possible exergitic and energetic efficiencies.
i. Turbine inlet pressure,
ii. Turbine inlet temperature,
iii. Reheat pressure ratio,
iv. Reheat temperature ratio,
v. Deaerator Pressure 
vi. Boiler flue gas inlet temperature

vii. Number of feedwater heaters

Also developed a software code by using Matlab software to calculate the steam parameters at supercritical and ultra-supercritical conditions.

2.1 Model Power Plant Description: A software simulated model of a Ultra supercritical power plant, is developed by using Matlab R2014a. While developing this model, the fundamental principles related to combustion of coal, mass balance, energy balance, energy destruction, exergy principles etc., are being considered.

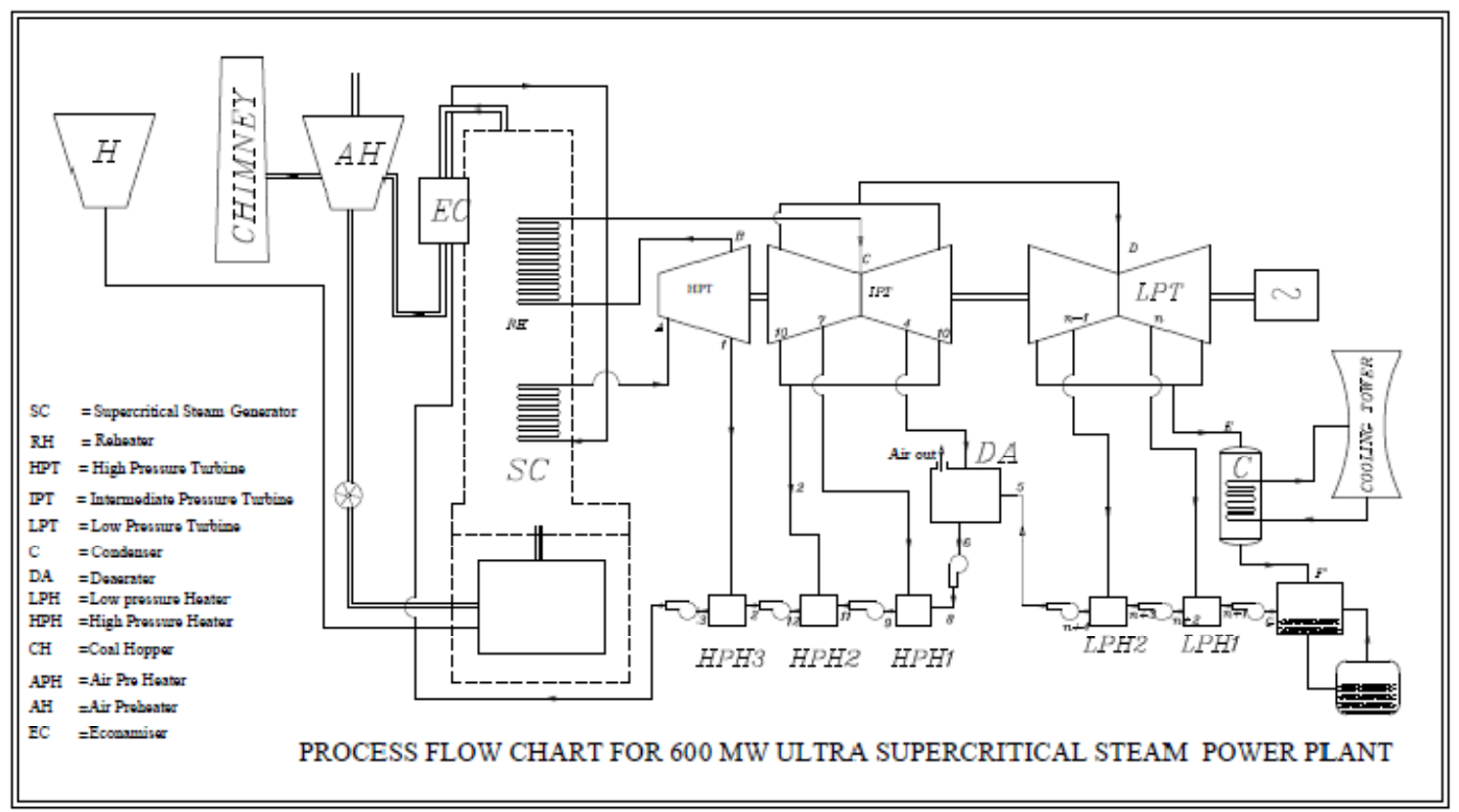

Fig 1. Schematic diagram of USC steam power plant

The fig1 indicates the schematic diagram of USC steam power cycle with reheat - varying regeneration heaters.

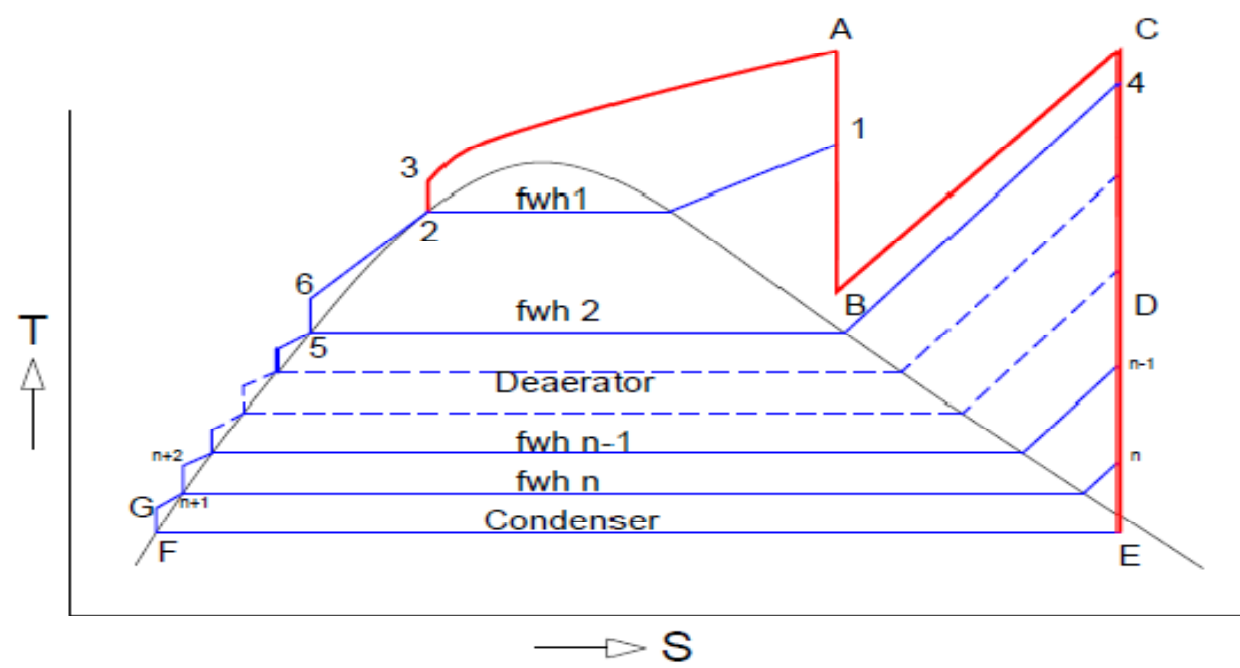

Fig 2. T-s diagram for USC power plant

The fig. 2 shows the T-S diagram for the considered model of USC power plant processes. 


\section{Specifications of the Plant.}

1. Power plant Capacity $=600 \mathrm{MW}$

2. HP Turbine Inlet Pressure $=320$ bar

3. HP Turbine Inlet Temperature $=670^{\circ} \mathrm{C}$

4. The isentropic efficiency of the Steam Turbine $=85 \%$

5. Reheating stages $=$ Single stage

6. Number of feedwater heaters 1 to ' $n$ '

7. Pump efficiency $=90 \%$

8. Condenser Pressure $=0.04 \mathrm{bar}$

9. Deaerator pressure $=160 \mathrm{bar}$

10. Heat and pressure losses during heating and expansion are not considered for this study.

\subsection{The Governing Exergy and Energy Equations used in the Ultra-Supercritical (USC) Model Power plant:}

The schematic layout of the ultra-supercritical steam thermal power plant considered for analysis in this study is shown in Fig 1. The corresponding thermodynamic cycle for the plant is shown on a T-s diagram in Fig 2. The feed water heaters in this plant are of open type; i.e. the bled steam is directly brought into contact with the feed water.Since the two streams are directly mixed in these heaters, a separate feed pumpis provided for each heater to increase the pressure of the feed water to the same level as that of the steam tap used for that feed water heater. As can be seen from these figures the number of feed water heaters is left as a variable parameter ' $n$ ' and thus the both the number feed water heaters as well as the number of stations at which properties are monitored in the plant are also variables. The numbering of the stations is done in such a way that starting from the first feed water heater, consecutive numbers are assigned to the steam bleed, the feed water heater exit, which is also the inlet for the feed pump which follows that heater, and the exit of the said feed pump. Thus station 1 and 2 are the steam bleed and exit stream of the feed water heater 1 , station 4 in the feed water inlet (also the exit from and station 3 is the exit of the first feed pump which is also the inlet to the boiler. For an intermediate feed water heater ' $\mathrm{i}$ ' the steam bleed will be from station ' $3 \mathrm{i}-2$ ', water inlet will be from station ' $3 \mathrm{i}+3$ ' and exit will be station ' $3 \mathrm{i}-1$ '. Similarly, for feed water heater ' $\mathrm{i}$ ', the inlet and exit are ' $3 \mathrm{i}-1$ ' and ' $3 \mathrm{i}$ ', respectively. In addition, the turbine inlet, re-heater inlet, re-heater exit, turbine exit, and condenser exit are termed as stations 'A', 'B', 'C', 'D', 'E','F', and 'G' respectively.

The governing equations for each of the components in the steam power plant could be derived from the general steady flow mass, energy and exergy equations for a control volume given by Moran and Shapiro[7] as:

$$
\begin{aligned}
& \sum_{i} m_{i}=\sum_{e} m_{e}(1) \\
& \dot{Q}_{c v}+\sum_{i} m_{i}\left(h_{i}+\frac{v_{i}^{2}}{2}+z_{i} g\right)=\dot{W}_{c v}+\sum_{e} m_{e}\left(h_{e}+\frac{V_{e}^{2}}{2}+z_{e} g\right) \\
& \sum_{\mathrm{j}}\left(1-\frac{\mathrm{T}_{0}}{\mathrm{~T}_{\mathrm{j}}}\right) \dot{\mathrm{Q}}_{\mathrm{cV}, \mathrm{j}}+\sum_{\mathrm{i}} \mathrm{m}_{\mathrm{i}} \mathbf{e}_{\mathrm{f}, \mathrm{i}}=\dot{\mathrm{W}}_{\mathrm{cv}}+\sum_{\mathrm{e}} \mathrm{m}_{\mathrm{e}} \mathbf{e}_{\mathrm{f}, \mathrm{e}}+\dot{\mathbf{E}}_{\mathrm{d}}
\end{aligned}
$$

Here $\mathbf{e}_{f}$ is the specific flow exergy which is defined as:

$$
\mathbf{e}_{\mathrm{f}}=\left(\mathrm{h}-\mathrm{h}_{0}\right)+\mathrm{T}\left(\mathrm{s}-\mathrm{s}_{0}\right)+\frac{\mathrm{v}^{2}}{2}+\mathrm{gz}
$$

In all the components of the cycle, the kinetic and potential energy changes could be neglected. The specific equations for the each of the individual components are given below.

\section{Boiler}

Here only the water tube banks of the boiler are taken as the system. Thus the system becomes a single inlet single outlet control volume. Also, there is no work interaction in the boiler. With these assumptions and the notations given in the figure A the following equations are obtained for the boiler.

$$
\begin{aligned}
& \dot{Q}_{\text {boiler }}=m_{A}\left(h_{A}-h_{3}\right)+m_{B}\left(h_{C}-h_{B}\right) \\
& \dot{\mathbf{E}}_{d, \text { boiler }}=\left(1-\frac{T_{0}}{T_{\text {boiler }}}\right) \dot{Q}_{\text {boiler }}+m_{A}\left(\mathbf{e}_{f, A}-\mathbf{e}_{f, 3}\right)+m_{B}\left(\mathbf{e}_{f, C}-\mathbf{e}_{f, B}\right)
\end{aligned}
$$

\section{Turbine}

The mass, energy and exergy equations for the turbine could be written as:

$$
\begin{aligned}
& m_{1}=m_{3}+\sum_{l=1}^{n} m_{3 l-2(7)} \\
& \dot{Q}_{\text {turb }}=m_{A} h_{A}+m_{C} h_{C}-m_{B} h_{B}-m_{B} h_{B}-\sum_{l=1}^{n} m_{3 l-2} h_{3 l-2}
\end{aligned}
$$




$$
\dot{\mathbf{E}}_{d, t u r b}=\left(1-\frac{T_{0}}{T_{t u r b}}\right) \dot{Q}_{t u r b}+m_{A} \mathbf{e}_{f, A}+m_{C} \mathbf{e}_{f, \mathrm{C}}-m_{B} \mathbf{e}_{f, B}-m_{D} \mathbf{e}_{f, D}-\sum_{l=1}^{n} m_{3 l-2} \mathbf{e}_{f, 3 l-2}-\dot{W}_{t u r b}
$$

\section{Condenser}

As was done in the case of the boiler, only the hot fluid circuit in the condenser is analyzed as the system of interest. With the usual assumptions, the energy and exergy equations for the condenser could be written as

$$
\begin{aligned}
& \dot{Q}_{\text {cond }}=m_{D} h_{D}-m_{E} h_{E} \\
& \dot{\mathbf{E}}_{\text {d,cond }}=\left(1-\frac{T_{0}}{T_{\text {cond }}}\right) \dot{Q}_{\text {cond }}+m_{D} \mathbf{e}_{f, D}-m_{E} \mathbf{e}_{f, E}
\end{aligned}
$$

\section{Feed Water Heaters}

The mass conservation equation for any feed water ' $i$ ' is given by:

$$
m_{3 i-2}+m_{3 i+3}=m_{3 i-1} \quad \text { (12) }
$$

The energy equation for the feed water heater ' $\mathrm{i}$ ' is:

$$
m_{3 i-2} h_{3 i-2}+m_{3 i+3} h_{3 i+3}=m_{3 i-1} h_{3 i-1}
$$

The exergy equation is:

$$
\dot{\mathbf{E}}_{d, H i}=m_{3 i-2} \mathbf{e}_{\mathrm{f}, 3 i-2}+m_{3 i+3} \mathbf{e}_{f, 3 i+3}-m_{3 i-1} \mathbf{e}_{f, 3 i-1} \text { (14) }
$$

\section{Pumps}

For any feed pump 'i' other than the last feed water heater is, the energy and exergy equations are

$$
\begin{aligned}
& W_{\text {pumpi }}=m_{3 i-1}\left(h_{3 i}-h_{3 i-1}\right) \\
& \dot{\mathbf{E}}_{d, p u m p i}=m_{3 i-1}\left(\mathbf{e}_{f, 3 i}-\mathbf{e}_{f, 3 i-1}\right)-W_{\text {pumpi }}
\end{aligned}
$$

The mass, energy and exergy equations for the last feed pump are given respectively by:

$$
\begin{aligned}
& W_{\text {pumpn+1 }}=m_{E}\left(h_{3 n-1}-h_{E}\right) \\
& \dot{\mathbf{E}}_{d, p u m p n+1}=m_{E}\left(\mathbf{e}_{f, 3 n-1}-\mathbf{e}_{f, E}\right)-W_{\text {pumpn }+1}
\end{aligned}
$$

\section{Overall Performance}

The net amount of work generated in the power plant is given by:

$$
W_{\text {plant }}=W_{\text {turb }}-\sum_{l=1}^{n+1} W_{\text {pumpi (19) }}
$$

The efficiency of the plant can be calculated as:

$$
\eta_{\text {plant }}=\frac{W_{\text {plant }}}{\dot{Q}_{\text {boiler }}}
$$

The exergy efficiency of the plant is given by:

$$
\eta_{\text {plant }}=\frac{W_{\text {plant }}}{\left(1-\frac{T_{0}}{T_{\text {boiler }}}\right) \dot{Q}_{\text {boiler }}} \text { (21) }
$$

The total exergy destruction in the plant is given by:

$$
\dot{\boldsymbol{E}}_{d, \text { plant }}=\stackrel{\sum \dot{\boldsymbol{E}}_{d}}{\text { all components }}
$$

2.3 MATLAB Code for the model: A computer code was developed using the scripting language MATLAB to solve the model equations given in section 2.2. The code is written such that it takes the turbine inlet temperature and the pressure ratios for various stages of expansion as the input and calculates the mass, energy and exergy balances for each of the components to determine the thermodynamic performance characteristics of various components in the system. The amount of steam taken from each bleed is computed by assuming that in each feed water heater the condensate is heated to the saturation temperature at the corresponding pressure. Isentropic efficiencies of the turbines are assumed to be $85 \%$. The net work output of the cycle is then computed. The mass flow rate of steam in the power plant is computed based on the total power generated by the plant and the specific work output of the cycle.Energy and exergy losses in each of the components are then estimated. The reheat pressure ratio and the reheat temperature are also given as input parameters and their effect on the cycle performance is analyzed.

2.4 Properties of steam:Steam properties at any given state are required for solving the model equation given in section 2.2. For this purpose, MATLAB subroutines were developed which can compute the steam properties for various phases including supercritical and ultra-supercritical regions. While developing the software program, the correlations from IAPWS-IFW7[6] are used. These subroutines are written such the any required property for the steam in single phase regions can be retrieved if the state of the steam is fixed by assigning two independent properties. For two phase mixture regions, the saturation properties can be obtained by giving either temperature or pressure. Alternatively, if we need the properties of the mixture the state of the 
mixture must be fixed by giving two independent properties. The computed property values are verified against the data provided by IAPWS-IFW7[6] and found to be accurate to at least five digits. The subroutines are then called by the MATLAB code described in section 2.3 whenever some property of steam is required given any two other independent properties.

\section{RESULTS AND DISCUSSION}

The outcomes of the simulated power plant on the exergy analysis and energy analysis are validated with the referenced values of an existing power plant of NTPC. This verified and validated program is run at elevated turbine inlet pressures and temperatures or Ultra-Supercritical conditions by varying the number of feedwater heaters, pressures of steam bleeding given to the heaters and deaerator. It is observed that the thermodynamic cycle efficiency increases with the addition of feedwater heater. Also it is observed that the rate of increase in efficiency is decreased with the increase in number of feedwater heaters. The above simulation program is run for the various turbine inlet temperatures, reheat temperature ratios, reheat pressure ratios, deaerator pressures, furnace inlet temperatures etc

\subsection{Addition of single feedwater heater - the effect of bled steam temperature ratio / pressure ratio on Rankine cycle efficiency.}

The fig.3indicates the exergy destruction in the boiler with the bled steam temperature orPressure ratio. The exergy destruction in the boiler primarily occurs due to combustion of fuel and heat transfer. There is no linear relationship between the exergy destruction and bled steam pressure ratio. Where as, it is observed that with the increase in bled steam pressure ratio, there is a reduction in exergy destruction. The cumulative exergy destruction in boiler is maximum i.e. $48 \%$ and it occurs at the bled steam pressure ration of 0.45 .

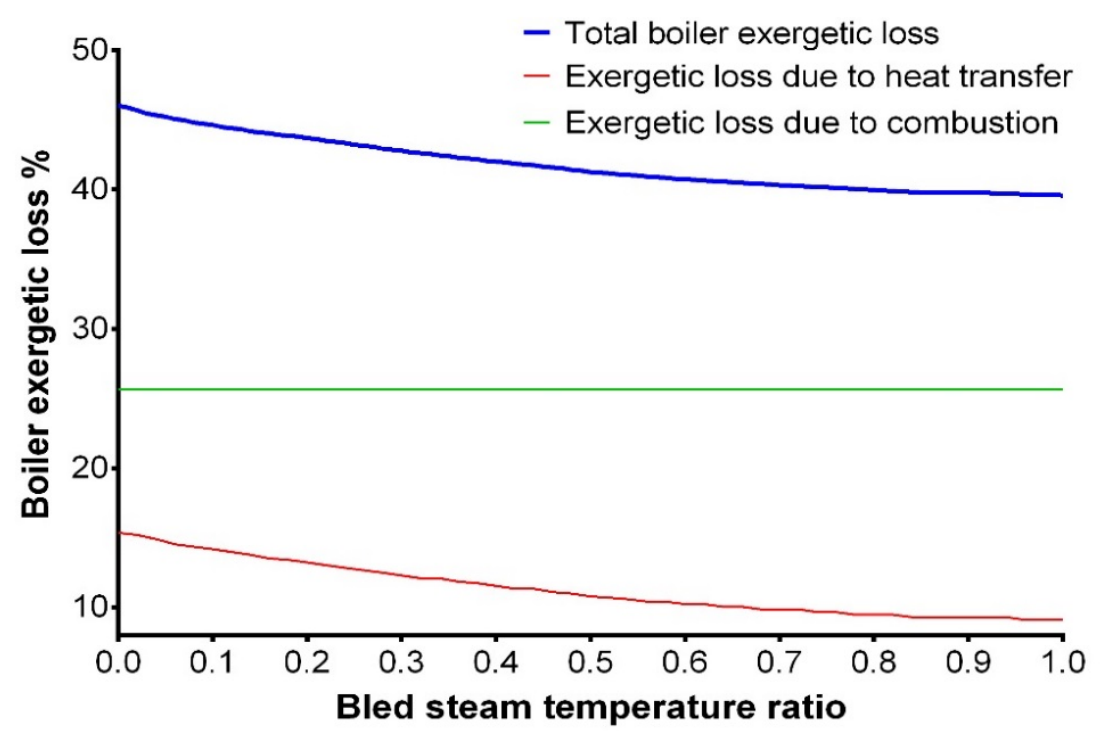

Fig.3. Impact of reheat temperature ratio on exergitic loss in boiler with a singlefeedwater heater

The fig.4 demonstrates the effect of bled steam temperature ratio on USC steam cycle with single feedwater heater. It is observed the cycle efficiency is maximum up to certain steam bled pressure condition. It is seen that the work output would be reduced due to the bleeding but it simultaneously lowers the heat rate supplied to the boiler. Which caused the increase in efficiency. And this increase is significant till the pressure ratio reaches 0.42 then it is observed that the efficiency is almost equal with the system without regeneration. The optimum pressure ratio for the thermal power plant with single feedwater heater is found as 0.42 . 


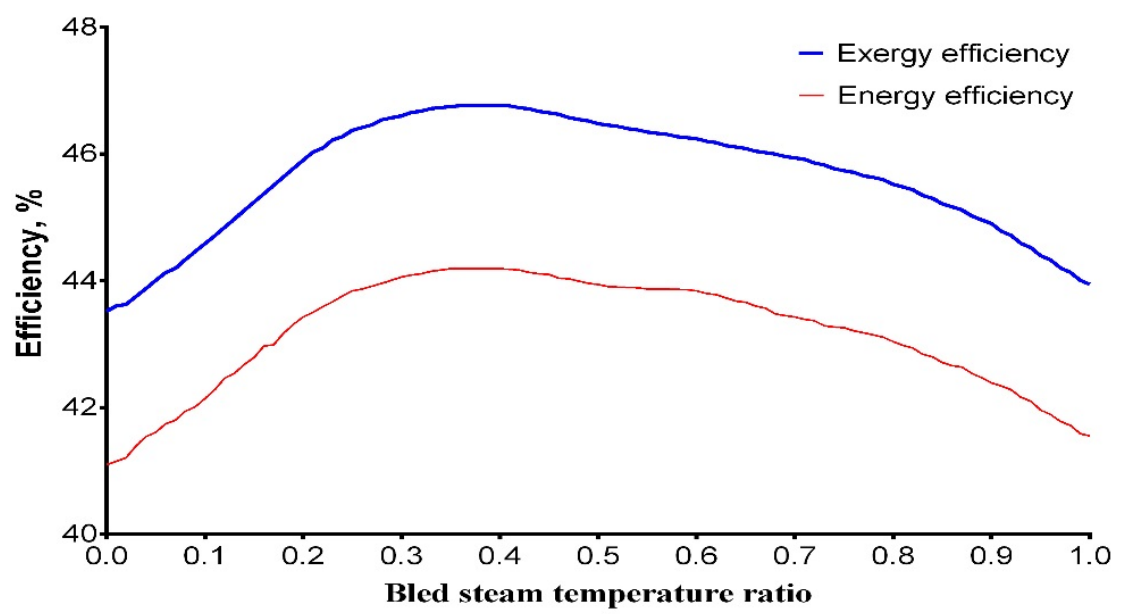

Fig.4. Impact of bled steam temperature ratio on cycle efficiency

\subsection{Addition of number of feedwater heaters - the effect of bled steam pressure ratio on Rankine cycle efficiency:}

The effects of reheat pressure ratio, turbine inlet temperature, turbine inlet pressure, flue gas inlet temperature, flue gas exit temperature etc., by adding ' $n$ ' number of feedwater heaters are analyzed on the performance of the rankine cycle at USC steam condition. These results obtained are with The mathematical equations are being used while calculating the energy and exergy efficiencies. And the results are verified with an existing NTPC power plant.

The exergitic loss in boiler by varying the reheat pressure ratio is demonstrated in fig 5 . It is observed that the exergitic loss or destruction in boiler is maximum when the power plant operates with no feedwater heater. With the addition of single feedwater heater, it could be observed that there is significant reduction in exergy loss in boiler. By varying the number of feedwater heaters it can be seen that there is further reduction in exergy destruction. But with the addition of more than eight number of feedwater heaters, a little significance can be observed.

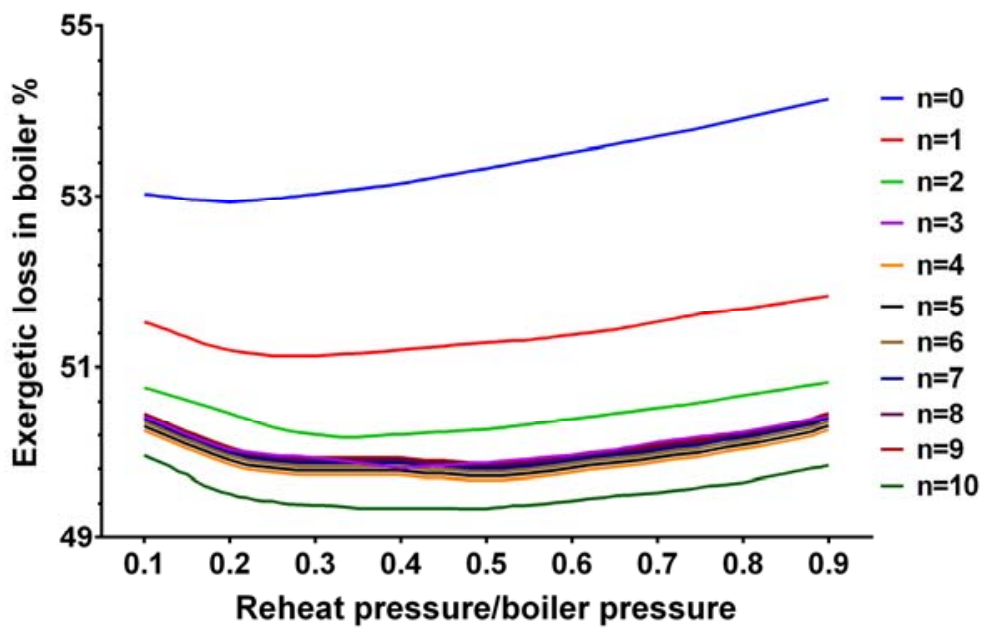

Fig 5. Impact of variation in reheat pressure and number heaters on exergitic loss in boiler

The demonstration shown in fig 6, indicates the effect of reheat pressure ratio with varying number of feedwater heaters on exergy efficiency. The reheat pressure ratio considered are 0.1 to 0.9 . When the reheat pressure is lowered, the cycle efficiency would be increased. But when the reheat pressure ratio (i.e ratio between reheat pressure to initial boiler pressure), is between 0.15 to 0.24 the efficiency would be maximum and then it would be reduced gradually. When the reheat pressure ratios are too low i.e less than 0.02 there would be less cycle efficiency than the cycle without reheating. 


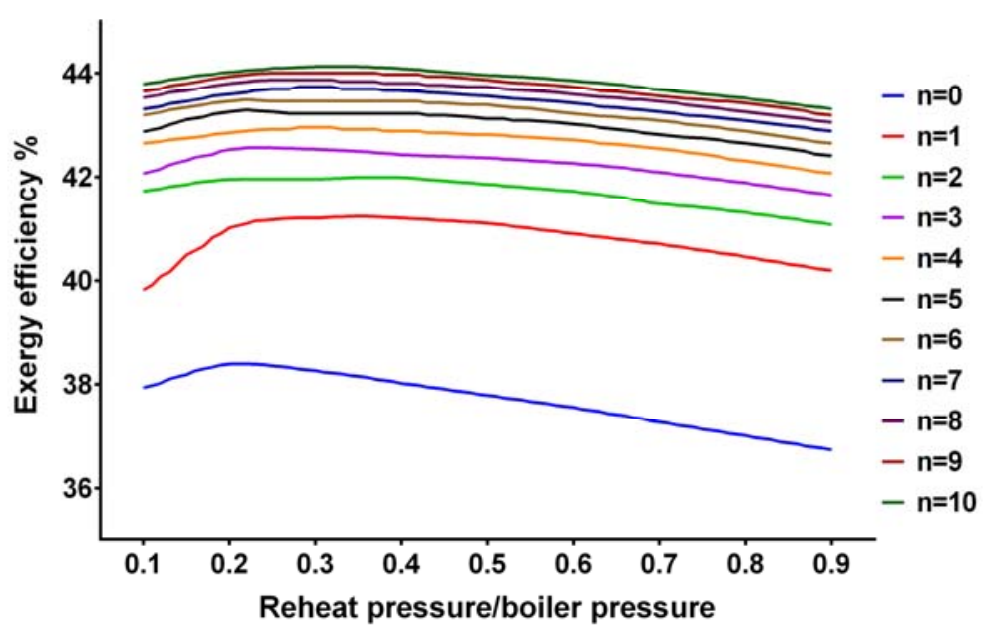

Fig 6: Impact of reheat pressure and varying thenumber of heaters on exergy efficiency

The effect of turbine inlet temperature on the exergy efficiency of the USC steam power cycle by varying the number of feedwater heaters is demonstrated in fig 7. The increase in exergy efficiency is found with the increase in turbine inlet temperature which is showed for single heater to $n$ number of regenerative heaters. This addition of regenerative heaters reduces the irreversibility and also decreases the exergy destruction.

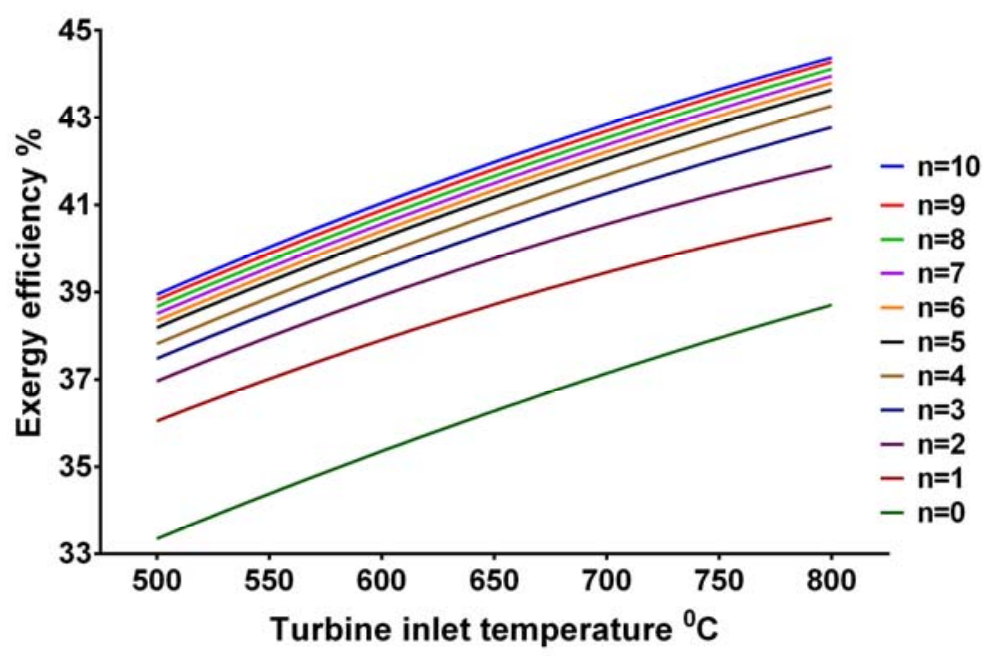

Fig. 7. Impact of turbine inlet temperature with varying number of heaters on exergyefficiency

The significance of the selected turbine inlet temperature range and adding the number of feedwater heaters, on the exergy increase is shown in the fig.7. There is a significant increase in exergy efficiency with the increase turbine inlet temperature and with the addition of first feedwater heater. But this increase is considerably less with the addition of more number of heaters which is observed the exergy increase is almost same with the addition of ninth and tenth heater. So the optimized number of feedwater heaters for the SC and USC power cycle is nine. As the enthalpy supercritical and ultra-supercritical steam at elevated temperatures is high the resulted efficiencies also high which is demonstrated in foresaid figure.

The effect of number of feedwater heaters and boiler pressure on the exergy efficiency is demonstrated in fig. 8. It may be visualized that there would be increase in efficiency with the increase in number of feedwater heaters and turbine inlet pressure. As the steam at elevated pressures contains higher enthalpies which resulted higher exergy and energy efficiencies. But it is also found that the addition of first feedwater heater there is considerable increase in exergy efficiency but as the number increases the increase in efficiency decreased significantly. Keep on adding the number feedwater heaters it is found that after seven, eight nine and ten additional heaters the increase in exergy is less significant. But predominantly this increase is further less significant with the addition of tenth heater. And therefore the optimum number of feedwater heaters in SC and USC power plants is nine. For the selected range of pressures and nine heaters the increase in exergy is $20 \%$ i.e from $36 \%$ to $56 \%$ 


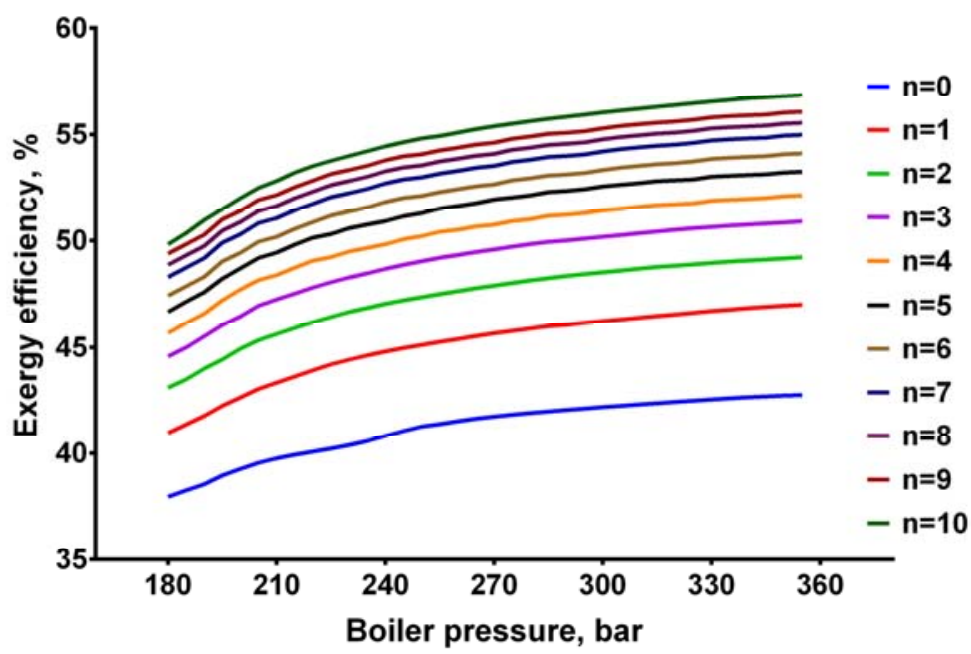

Fig. 8. Impact of boiler inlet pressure and number of feedwater heaters on exergy efficiency.

The dot comparison between the figures 7 and 8 lets us, to understand that the influence of higher turbine temperatures plays a significant role in increasing the exergy efficiency than the higher turbine pressure limits.

The influence of flue gas inlet temperatures, addition of number of feedwater heaters and its combined effect on exergy efficiency is found little significant. Those influences are demonstrated in fig. 9. With the increase in furnace inlet temperature there is an increase in temperature of steam and also rate of steam generation. And these increased flow rates and high temperatures increases the work output and also efficiencies.

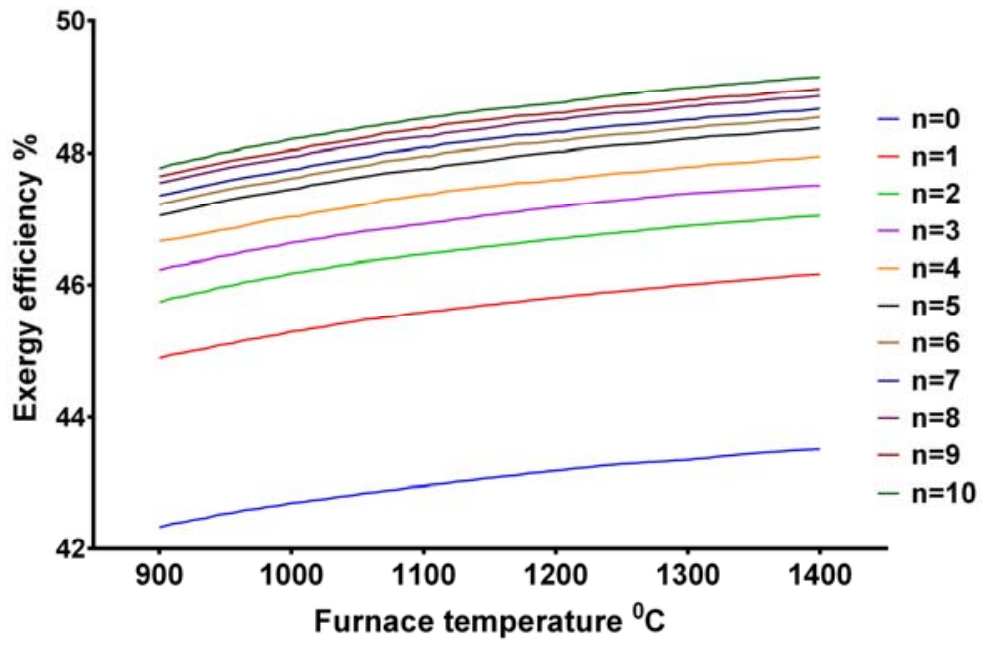

Fig.9. Impact of furnace inlet temperature and number of feedwater heaters on exergyefficiency of the USC cycle

The exergy destructions at various thermal equipment's with varying number of heaters is shown in fig.10. The major exergy destruction is accounted during combustion in furnace and heat exchange between the flue gases and fluid flowing through the evaporative tubes. 


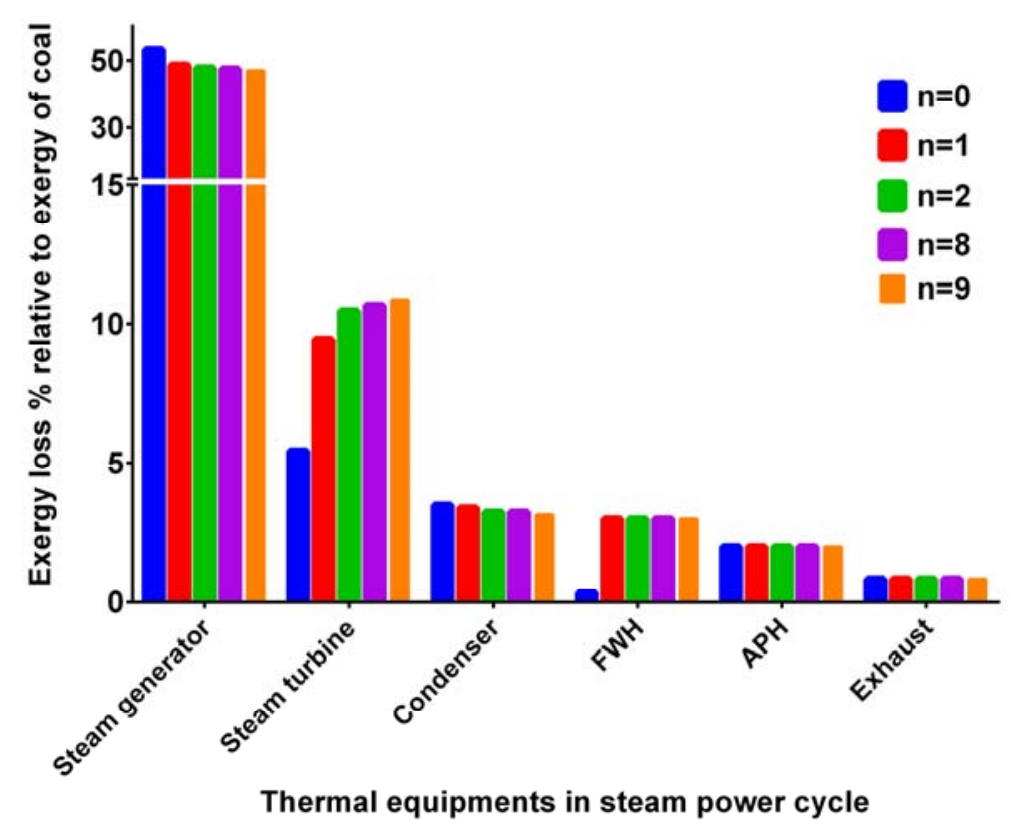

Fig 10. Comparative graph of exergitic loss in various thermal equipment's

The exergy destruction during combustion could be reduced by adopting various modern combustion techniques such as fluidized bed combustion methods (PFBC, CFBC) and employing the cyclones. The exergy destruction in boiler could be decreased with the increase in number of heaters and it could be increased in turbine. This exergy loss in condenser would be reduced with the addition of number of regenerative heaters. But this exergy destruction in economizer and air preheater would be reduced by employing the number of feedwater heaters as the energy convertibility increases.

\subsection{Addition of Deaerator - the effect of deaerator pressure on exergitic efficiency:}

The fig.11 shows the impact of deaerator pressure on exergitic efficiency with varying number of feedwater heaters. And it is clearly found that the addition of deaerator only removes the insoluble gasses from the feedwater. But simultaneously increases the feedwater temperature same as feedwater heater. The exergitic efficiency is almost equal without deaerator and with deaerator.

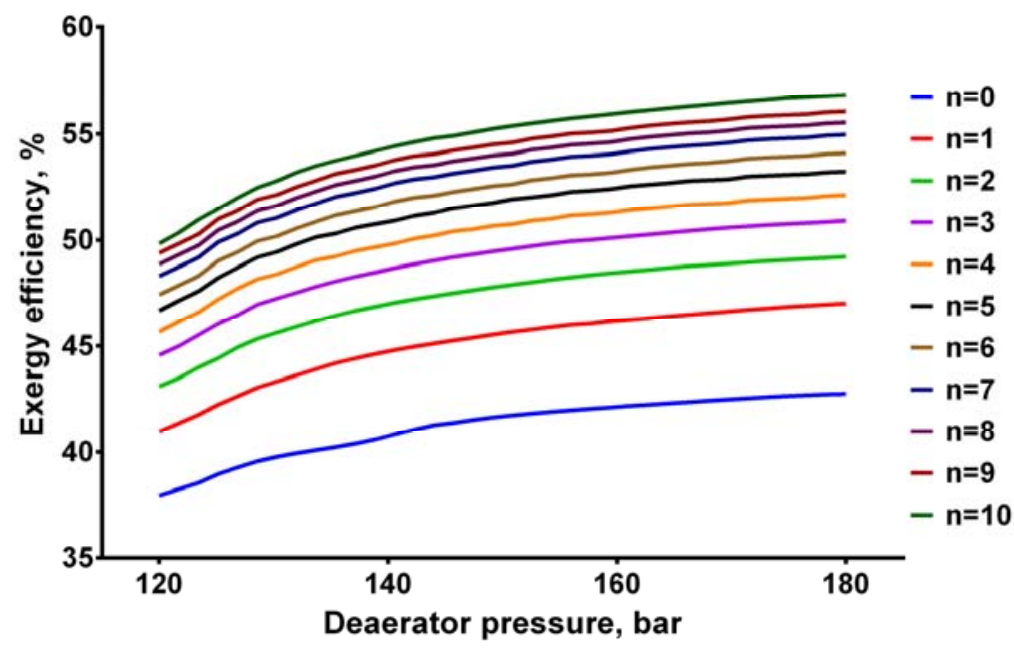

Fig. 11. Impact of deaerator pressure on exergy efficiency with varying number of feedwater heaters. 


\section{III.CONCLUSION}

The following points are derived during the parametric study and optimized the various technical parameters for the selected 600MW Rankine cycle based Ultra Supercritical (USC) power plant. The energy and exergy destructions and efficiencies are estimated by varying the number of feedwater heaters, bled steam pressures and deaerator pressures of power plant. The exergy efficiency of USC power cycle with single feedwater heater is found $46 \%$, with eight feedwater heaters it is $55 \%$ and with nine feedwater heaters it is $56 \%$. But with the addition of tenth feedwater heater it is observed same exergy as the nine feedwater heaters. So by avoiding the addition one more feedwater heater one could reduce the cost of plant setup. The exergy efficiency can be seen maximum at steam pressure ratio of 0.45 . Hence this study concludes that by employing nine number feedwater heaters, the exergy destruction in a USC Rankine cycle power plant could be reduced which we can treat as optimum number. And the usage of deaerator not only removes the dissolved gases such as oxygen and carbon dioxide, but also acts as a feedwater heater in the series of heaters. It also can be seen the impact of deaerator on reducing the irreversibility and increasing the exergy efficiency.

\section{References}

[1] L. Z. G. X. Y. F. Yuanyuan Li, "Thermodynamic analysis and optimization of a double reheat system in an ultra-supercritical power plant,” Elsevier, Energy, pp. 202-214, 2014.

[2] A. A. a. V. Sandhya Hasti, “Exergy analysis of Ultra Super-Critical Power Plant,” Elsevier, Energy Precidea, vol. 37, pp. 2544-2551, 2013.

[3] Z. L. Z. Y. Zhi Li, "Energy and exergy Analysis for three type $500 \mathrm{MW}$ steam power plant," Applied mechanics and materials, Vols. 148-149, pp. 1131-1136, 2011.

[4] R. M.A., "Energy and exergy based balance comparison of coal fired and nuclear power plant,” Elsevier, energy precedia, pp. 25442551, 2013.

[5] R. a. D. Govindarajulu, Parametric study and thermodynamic analysis of Ultra supercritical rankine cycle power plant of 800MW power generation with feedwater heaters and deaerator, Vol 6, Issue 8 ed., IJETAE, Aug 2016.

[6] J. R. Cooper, "IAPWS-IF97,” International Association for the Properties of Water and Steam, Lucerne, Switzerland, 1997.

[7] M. J. M. a. H. N. Shapiro, Fundamentals of engineering thermodynamics, West Sussex, UK: John Wiley \& sons Inc, 2006.

[8] A. Bejan, Fundamentals of exergy analysis, entropy generation minimization and the generation of flow architecture, North Carolina, U.S.A: John Wiley \& Sons, 2002.

[9] IEA, “Energy statistics 2015,” Govt of India press release, March 2015.

[10] A. I. Kalina, “Combined cycle system with novel bottoming cycle,” Journal of engineering for gas turbine and power , vol. 106, pp. 737-742, 1984.

[11] I. D. Marc A. Rosan, “Exergy as the confluence of energy, environment and sustainable development,” Elsevier, Exergy an International journal, no. 2001, pp. 3-13, 2001.

[12] M. E. Moran, Exergy Analysis: Principles and Practice, Ohio, USA: J. Eng. Gas Turbine power, 1994.

[13] OECED/IEA, "Report on Power Generation from coal," IEA Project report on measuring and reporting efficiency performance and CO2 emmissions, 2010.

[14] T.J., "The exergy method of thermal power plant analysis,” in Krieger Publishing company, Malabar, FL, 1995.

[15] W. C. J. D. A. K. J. K. H. K. A. Wagner, The IAPWS Inudustrial Formulation 1997 for the Thermodynamic properties of water and steam, J. Eng. Gas Turbines \& Power , 2000. 